\title{
Left Varicocele Revealing a Nutcracker Syndrome: A Case Report and Review of Literature
}

\author{
Hicham El Bote*, Oussama Ziouani, Abdelilah El Alaoui, Hachem El Sayegh, Ali Iken, \\ Lounis Benslimane, Yassine Nouini \\ Department of Urology A, Ibn Sina University Hospital, Rabat, Morocco \\ *Corresponding author: dr.hicham.el.bote@gmail.com
}

\begin{abstract}
Nutcracker syndrome (NCS) is a rare entity defined by the symptomatic hypertension of the left renal vein (LRV) compressed in the majority of cases between the superior mesenteric artery and the aorta. Hematuria, pelvic or back pain and left varicocele are the most commonly symptoms. Doppler ultrasound, computed tomography (CT) and selective left renal vein phlebography are useful to confirm the diagnosis. Treatment criteria are not well established, however for asymptomatic patients with no haematuria, the treatment remains conservative. We report the case of a 17-year-old man, with an intermittent left flank pain for 4 years and increasing volume of the left testicle for 8 months.
\end{abstract}

Keywords: nutcracker syndrome, varicocele

Cite This Article: Hicham El Bote, Oussama Ziouani, Abdelilah El Alaoui, Hachem El Sayegh, Ali Iken, Lounis Benslimane, and Yassine Nouini, "Left Varicocele Revealing a Nutcracker Syndrome: A Case Report and Review of Literature.” American Journal of Medical Case Reports, vol. 5, no. 5 (2017): 110-112. doi: 10.12691/ajmcr-5-5-1.

\section{Introduction}

Nutcracker syndrome (NCS) is a rare entity defined by the symptomatic hypertension of the left renal vein (LRV) compressed in the majority of cases between the superior mesenteric artery and the aorta. Because of the several clinical manifestations, like: haematuria, mild to moderate proteinuria, sometimes varicocele in males, and pelvic congestion in females, it is usually diagnosed after exclusion of other diseases. The treatment remains controversial and depend on the individual case and status of each patient and severity.

\section{Case Presentation}

A 17-year-old man with good past health presented an increasing volume of the left testicle for 8 months with intermittent left flank pain for 4 years without notion of hematuria.

Clinical examination in the standing position found a visible and palpable varicocele (Grade 2, according to the classification of Dubin and Amelar), evident during the Valsalva maneuver in testicular color Doppler ultrasonography (Figure 1).

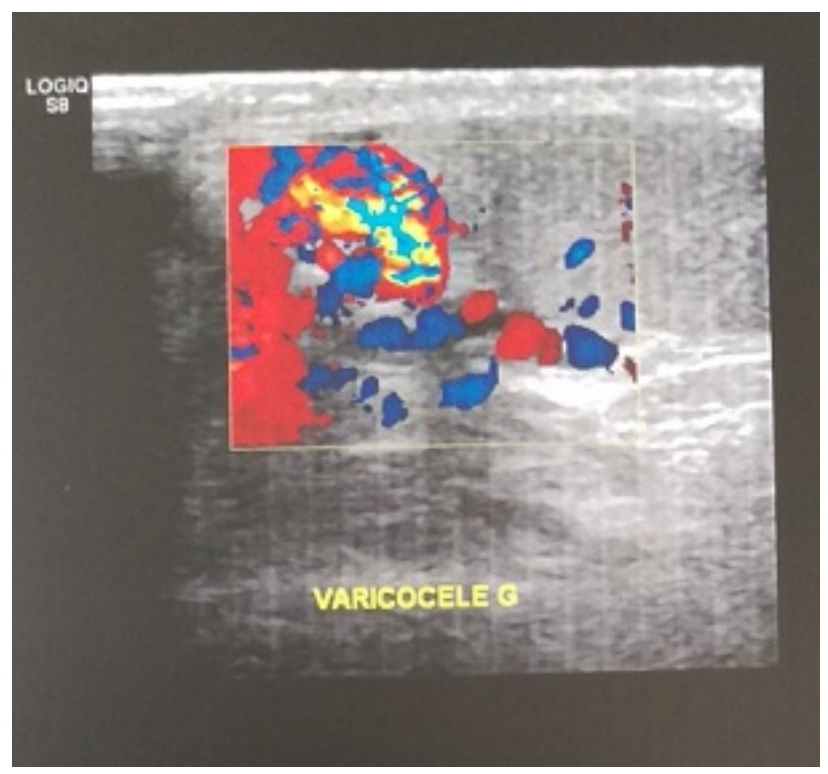

Figure 1. Testicular color Doppler ultrasonography: Left varicocele with varicosities that exhibit reflux only during the Valsalva maneuver 


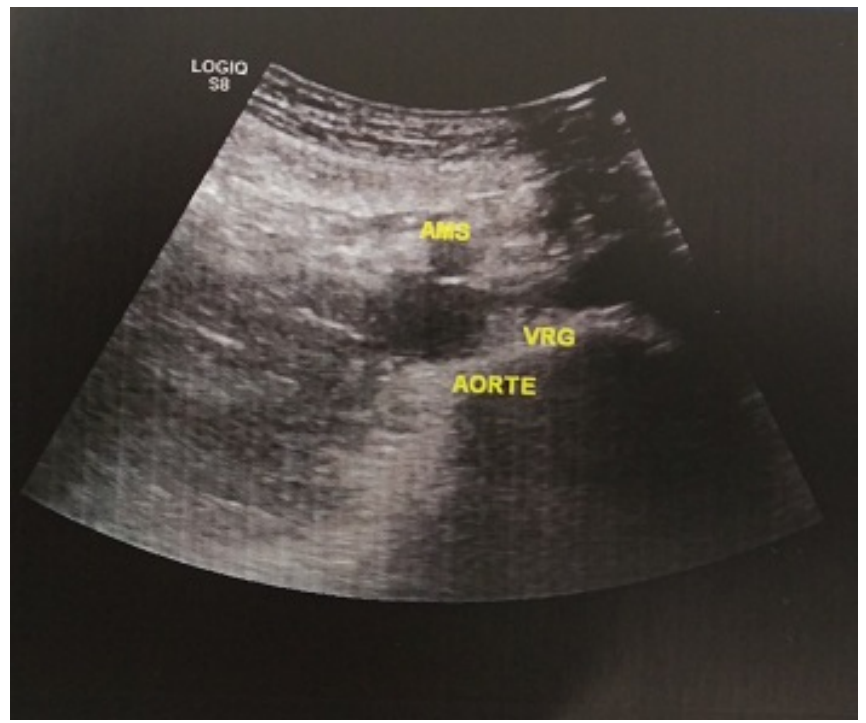

Figure 2. Abdominal ultrasonography: Compression of the left renal vein between the superior mesenteric artery and the aorta
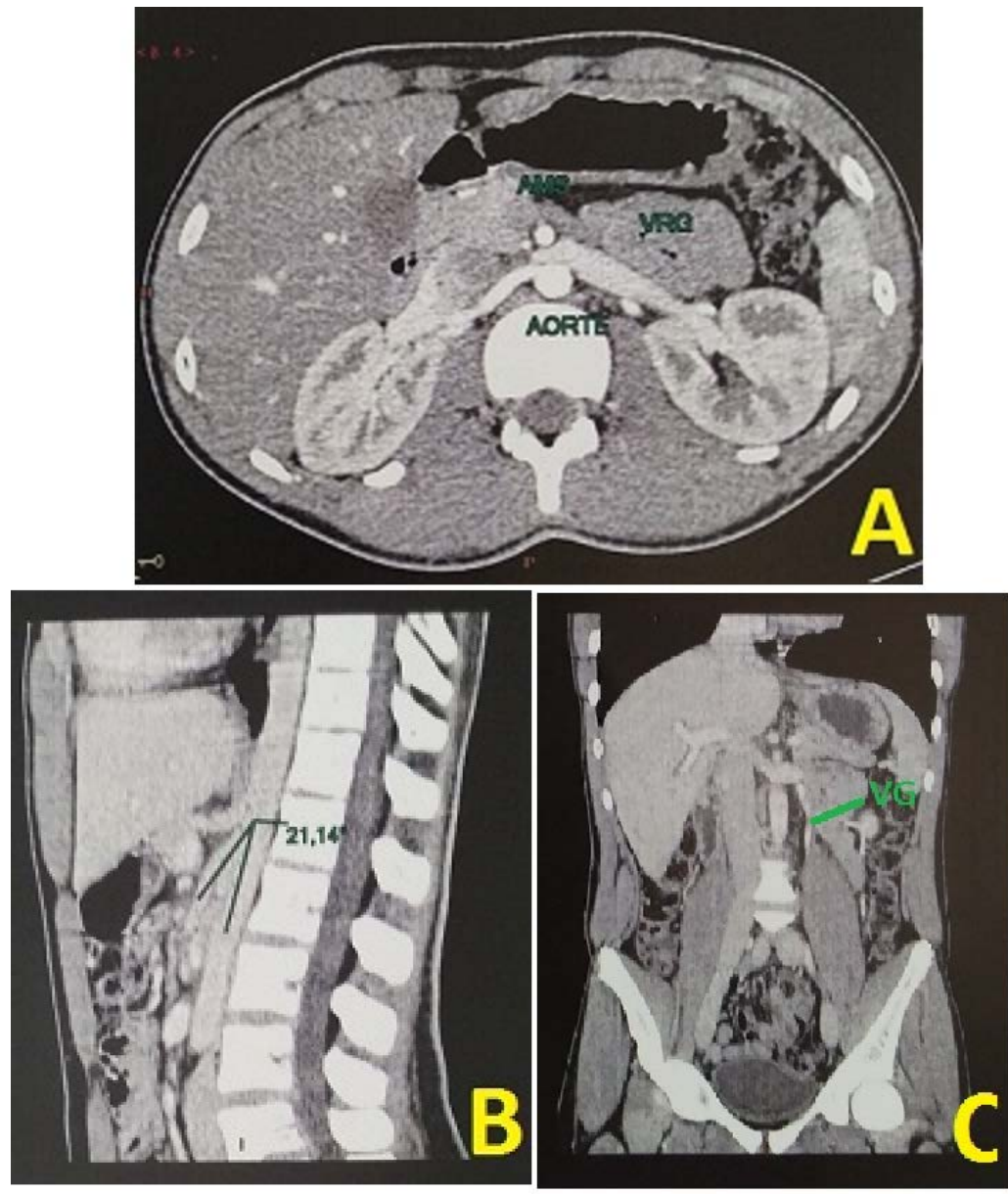

Figure 3. Abdominal CT scan: 3A: Cross-sectional view 3B: Sagital view showing the compression of the left renal vein between the superior mesenteric artery and the aorta, $3 \mathrm{C}$ : Coronal view showing the distension of the left genital vein

Abdominal ultrasonography showed compression of the left renal vein between the aorta and the superior mesenteric artery (Figure 2).

Abdominal CT confirmed the diagnosis of a nutcracker syndrome (Figure 3) by visualizing the distension of the left genital vein.

The patient underwent a laparoscopic varicocelectomy and conservative treatment was adopted for the compression of the left renal vein.

\section{Discussion}

Nutcracker syndrome (NCS) was first described by Grant [1], who described the impingement of the left renal vein (LRV) by the superior mesenteric artery (SMA) against the aorta, comparing it to that of a nut within the jaws of a nutcracker. The first clinical case of NCS was acknowledged by El-Sadr and Mina in 1950 [2], and its management was first documented by de Schepper [3] and 
afterwards by Pastershank [4]. We must differentiate the nutcracker phenomenon (NCP), the anatomical identification of mesoaortic compression of the LRV, from the nutcracker syndrome, the clinical manifestation of mesoaortic compression of the LRV. NCP is subdivided into anterior subtype, that refers to mesoaortic compression of the LRV, and posterior subtype, caused by the compression of a retroaortic LRV between the aorta and vertebrae [5].

The compression of the LRV in the fork between the abdominal aorta and proximal superior mesenteric artery causes left renal venous hypertension, which subsequently leads to the development of collateral veins with intrarenal and perirenal varicosities, and may result in several signs and symptoms such as pain in the flanks, hematuria, left varicocele, fatigue, proteinuria, pelvic congestion [6,7].

The varicocele is a vascular lesion commonly associated with infertility defined as an abnormally dilated and serpiginous pampiniform venous plexus within the scrotum, characterized by retrograde flow in the internal spermatic vein [8].

The LRV is compressed in more than half of the patients with varicocele $[9,10]$.

Because of common symptoms, it is usually diagnosed after exclusion of other diseases, like: benign or malignant testicular tumor, renal cancer, and inferior vena cava thrombosis [11].

Enhanced CT, MRI, Doppler ultrasound, and left renal venography are helpful in establishing the diagnosis of the nutcracker syndrome [12].

The diagnosis is made when a reduction of left renal vein diameter is greater than 50\% [13].

Treatment depends on the severity of the pathology and symptoms. Traditionally, persistent hematuria, lumbar or incapacitating pelvic pain or the presence of severe congestive pelvic symptoms are treatment indications for NCS, with the exclusion of other differential diagnoses $[14,15]$. For asymptomatic patients, the treatment is conservative.

\section{Conclusion}

In the nutcracker syndrome anatomical changes generate no specific symptomatology. The diagnosis of the syndrome is often difficult and under diagnosed. Treatment decision should be based on the severity of symptoms, and the options are ranged from surveillance to nephrectomy.

\section{Conflict of Interests}

The authors declare that there is no conflict of interests regarding the publication of this paper.

\section{References}

[1] Grant J. Methods of Anatomy. Baltimore, Md, USA: Williams and Wilkens; 1937.

[2] El-Sadr A.R., Mina E. Anatomical and surgical aspects in the operative management of varicocele. Urol. Cutaneous. Rev. 1950; 54: 257-262.

[3] de Schepper A. Nutcracker phenomenon of the renal vein and venous pathology of the left kidney. J. Belge Radiol. 1972; 55: 507-511.

[4] Pastershank S. P. Left renal vein obstruction by a superior mesenteric artery. Canadian Association of Radiologists Journal. 1974; 25(1): 52-54.

[5] Kurklinsky A. K., Rooke T. W. Nutcracker phenomenon and nutcracker syndrome. Mayo Clinic Proceedings. 2010; 85(6): 552-559.

[6] Russo D, Minutolo R, Iaccarino V, Andreucci M, Capuano A, Savino FA. Gross hematuria of uncommon origin: the nutcracker syndrome. Am J Kidney Dis 1998; 32:E3.

[7] Hanna HE, Santella RN, Zawada ET Jr, Masterson TE. Nutcracker syndrome: an underdiagnosed cause for hematuria? SD J Med 1997; 50:429-436

[8] Kim WS, Cheon JE, Kim IO, et al. Hemodynamic investigation of the left renal vein in pediatric varicocele: Doppler US, venography, and pressure measurements. Radiology 2006; 241: 228-234.

[9] M. Unlu, S. Orguc, S. Serter, G. Pekindil, Y. Pabuscu. Anatomic and hemodynamic evaluation of renal venous flow in varicocele formation using color Doppler sonography with emphasis on renal vein entrapment syndrome. Scand J Urol Nephrol, 41 (2007), pp. 42-46.

[10] A. Chait, K.W. Matasar, C.E. Fabian, H.Z. Mellins. Vascular impressions on the ureters. Am J Roentgenol Radium Ther Nucl Med, 111 (1971), pp. 729-749.

[11] Wang L., Yi L., Yang L. Dianogsis and surgical treatment of nutcracker syndrome: a single-center experience. Urology. 2009; 73: 871-876.

[12] Ekim M, Bakkaloglu SA, Tu"mer N, Sanlidilek U, Salih M. Orthostatic proteinuria as a result of venous compression (nutcracker phenomenon) a hypothesis testable with modern imaging techniques. Nephrol Dial Transplant 1999; 14(4): 826e7.

[13] Zhang H., Zhang N., Li M. Treatment of six cases of left renal nutcracker phenomenon: surgery and endografting. Chin. Med. J. (Engl.) 2003; 116: 1782-1784.

[14] O. Hartung, D. Grisoli, M. Boufi, I. Marani, Z. Hakam, P. Barthelemy, et al. Endovascular stenting in the treatment of pelvic vein congestion caused by nutcracker syndrome: lessons learned from the first five cases J Vasc Surg, 42 (2005), pp. 275-280.

[15] M.T. Menard, Nutcracker syndrome: when should it be treated and how? Perspect Vasc Surg Endovasc Ther, 21 (2009), pp. 117-124. 